\title{
Long-term outcomes of percutaneous coronary interventions within coronary artery bypass grafts
}

\author{
Rafał Januszek ${ }^{1}$, Zbigniew Siudak ${ }^{2}$, Artur Dziewierz ${ }^{3,4}$, Tomasz Rakowski, ${ }^{3,4}$, Dariusz Dudek ${ }^{3,5}$, \\ Stanisław Bartuś 3,4
}

\begin{abstract}
${ }^{1}$ Department of Clinical Rehabilitation, University of Physical Education, Krakow, Poland ${ }^{2}$ Faculty of Medicine and Health Sciences, Jan Kochanowski University, Kielce, Poland ${ }^{3} 2^{\text {nd }}$ Department of Cardiology and Cardiovascular Interventions, University Hospital, Krakow, Poland

${ }^{4} 2^{\text {nd }}$ Department of Cardiology, Jagiellonian University Medical College, Krakow, Poland ${ }^{5}$ Department of Interventional Cardiology, Jagiellonian University Medical College, Krakow, Poland
\end{abstract}

Submitted: 24 January 2018; Accepted: 22 March 2018;

Online publication: 30 January 2019

Arch Med Sci 2021; 17 (3): 628-637

DOI: https://doi.org/10.5114/aoms.2018.75608

Copyright () 2019 Termedia \& Banach

\section{Abstract}

Introduction: The long-term outcomes of percutaneous coronary interventions ( $\mathrm{PCls}$ ) within coronary artery bypasses are still poor as compared to those within native coronary arteries. Thus, we aimed to assess predictors of long-term clinical outcomes after PCls of coronary bypasses.

Material and methods: We enrolled 194 patients after PCls of coronary artery bypasses at the mean age of $69.5 \pm 8.3$ years $(73.2 \%$ male). The primary study endpoint was a combination of target-vessel revascularization (TVR), target-lesion revascularization (TLR), myocardial infarction (MI), stroke, coronary artery bypass grafting (CABG) and death. The mean follow-up was $964 \pm 799.1$ days and was completed among 156 patients. Multivariate analysis was used to assess determinants of study endpoints during follow-up. Moreover, we compared survival curves according to the type of $\mathrm{PCl}$ and presence of anti-embolic protection. Results: The primary endpoint of the study occurred in $59.7 \%$ of patients after the mean time of $669.6 \pm 598.7$ days. The TVR occurred in $37.9 \%$ of individuals, TLR in $24.2 \%, \mathrm{MI}$ in $26.3 \%$, stroke in $4.2 \%$, CABG in $2.1 \%$ and death in $30.5 \%$ of patients. In Cox multivariate analysis, $\mathrm{PCl}$ of two or more bypasses $(p<0.01)$, post-dilatation $(p<0.05)$ and no-reflow $(p<0.05)$ were the independent determinants of the primary study endpoint. No significant impact of anti-embolic protection devices on long-term outcomes was observed.

Conclusions: Percutaneous coronary interventions of two or more bypasses, post-dilatation and no-reflow are predictors of worse outcome in patients undergoing $\mathrm{PCl}$ within coronary artery bypass grafts.

Key words: percutaneous coronary intervention, coronary artery bypasses, long-term follow-up, clinical outcomes, determinants.

\section{Introduction}

The long-term success of surgical coronary revascularization is limited, as at 1 year, the incidence of one or more total saphenous vein graft (SVG) occlusions after on-pump bypass surgery has been reported to be as high as $41 \%$ [1]. Due to the very high risk of cardiac surgery re-operations, percutaneous coronary intervention $(\mathrm{PCl})$ is considered to be the

\author{
Corresponding author: \\ Stanisław Bartuś \\ $2^{\text {nd }}$ Department \\ of Cardiology \\ and Cardiovascular \\ Interventions \\ University Hospital \\ 17 Kopernika St \\ 31-501 Krakow, Poland \\ Phone: +48 124247170 \\ Fax: +48 124247180 \\ E-mail: stanisław.bartus@ \\ uj.edu.pl
}


preferred revascularization method of treatment in patients with SVG stenoses or occlusions [2]. However, $\mathrm{PCl}$ of SVGs remains technically challenging and is characterized by higher rates of periprocedural adverse events as compared to $\mathrm{PCl}$ of native coronary arteries [3]. Several typical complications of SVG interventions have been observed and investigated. One of the most common and influential consequences of SVG intervention on future outcomes is distal embolization. The incidence of distal embolization presented as the slow- or no-reflow phenomenon was estimated at $10 \%$ to $15 \%$ among patients with periprocedural angina and ischemic ST-segment changes [4]. Among the many factors, periprocedural complications were found to be associated with worse long-term outcomes in this group of patients [5]. Other well-studied factors likely to affect the outcomes of coronary artery bypass graft interventions include type of vessel, $\mathrm{PCl}$, balloon and stent, anticoagulation in the periprocedural period and after $\mathrm{PCl}$ or the presence and type of anti-embolic protection devices against distal embolization. These predictors seem to be mostly preponderant. However, several other periprocedural indices related to technical aspects and maneuvers appear to be at least similarly influential for outcomes after coronary artery bypass graft interventions [6-10].

Therefore, we aimed to investigate the impact of the often overlooked and underrated factors associated with outcomes in patients undergoing $\mathrm{PCl}$ s within bypass grafts.

\section{Material and methods}

Retrospectively, we collected data on 194 consecutive patients undergoing $\mathrm{PCl}$ within coronary artery bypass grafts at our department from 2008 to 2016 . At that time, about $1200-1400 \mathrm{PCl}$ procedures were performed in our department every year. Follow-up data were collected from outpatients' clinic documentation and by phone calls. The primary study endpoint included target-lesion revascularization (TLR), target-vessel revascularization (TVR), myocardial infarction (MI), cerebral stroke, coronary artery bypass grafting (CABG) and death.

\section{Statistical analysis}

Kaplan-Meier analysis was used for the primary endpoint assessment. Mantel-Cox and Breslow analyses were used for comparison between Kaplan-Meier curves. The data are expressed as means with standard deviations (SD), medians and interquartile ranges, and the percentage distribution, as appropriate. Both univariate and multivariate Cox proportional hazards models for study endpoints were constructed. Among the factors assessed in multivariate analysis, we included the number of bypasses treated with $\mathrm{PCl}$, type of artery bridged by graft, bypass age, type of the lesion treated with $\mathrm{PCl}$, thrombectomy, type of anti-embolic protection device and its use, presence of thrombus, location of the lesion in the graft (proximal, medial, distal), calcifications, type of stent, number of implanted stents, stent diameter and length, direct stenting, pre-dilatation, post-dilatation, maximal pressure of inflated balloon, residual stenosis > 10\%, TIMI flow after the procedure, no-reflow phenomenon, $\mathrm{PCl}$ of the second vessel, treatment with glycoprotein IIb/IIla inhibitor, and treatment with oral anticoagulants. Since the model could not achieve convergence for all the introduced predictors, following the relatively low number of events and data deficiencies concerning selected indices in the database, the analysis was limited to those potential predictors where there were fewer than eight missing results. This was done to increase test strength. For this reason, we excluded some factors with potentially less predictive impact for bypass restenosis including family history of cardiovascular events, the Global Registry of Acute Coronary Events (GRACE) score at admission, body mass index or Killip class stage. The log-rank test (Mantel-Cox) and Breslow test (generalized Wilcoxon) were used for comparison of major adverse cardiac and cerebrovascular event (MACCE) rates between particular types of $\mathrm{PCl}$ which included $\mathrm{PCl}$ with drug-eluting balloon (DEB), PCl with drug-eluting stent (DES) implantation, bare-metal stent (BMS) implantation and plain old balloon angioplasty (POBA) or failed $\mathrm{PCI}$. Additionally, those tests were used for comparison of the MACCE rates between patients treated with distal protection devices and without them.

\section{Statistical analysis}

Statistical significance was accepted at a 0.05 level of probability. The statistical analyses were performed using Statistica 10.0 software (Dell Software, Inc, Round Rock, TX, USA) and SPSS Statistics 24 (IBM, USA).

\section{Results}

The clinical characteristics of the overall group are presented in Table I. Data regarding the length of hospitalization were available for 175 (90.2\%), of whom hospitalization time $<7$ days was found in $93(53.1 \%)$ patients, and $\geq 7$ days in 82 (46.8\%) patients. The causes of prolonged hospitalization should be mainly sought as a greater burden of risk factors for cardiovascular disease expressed as EuroSCORE II, which was statistically significantly higher in the group of patients hospitalized longer $(13.2 \pm 14.3 \%$ vs. $11.1 \pm 15.1 \%, p=0.02)$ 
and greater impairment of the left ventricular systolic function expressed as left ventricular ejection fraction ( $41.6 \pm 14.0 \%$ vs. $46.7 \pm 13.3 \%, p=0.02)$. Additionally, patients with prolonged hospitalization were admitted to hospital insignificantly more often with myocardial infarction $(42.6 \% \mathrm{vs}$. $34.8 \%, p=0.28)$, kidney failure $(32.1 \%$ vs. $19.8 \%$, $p=0.11)$, Killip class II-IV (22.8\% vs. $14.3 \%, p=$ $0.45)$ and heart failure expressed as New York Heart Association (NYHA) class III-IV (14.8\% vs. $8.7 \%, p=0.21$ ). The clinical presentation of coronary artery disease and cardiovascular risk indices are presented in Table II. Pharmacological treatment at discharge from the hospital and periprocedural treatment with glycoprotein IIb/IIla inhibitors are presented in Table III.

Due to the fact that some of the patients included in the current study were sent to our center from tertiary catheterization laboratories, we did not repeat full coronary angiography, and primary

Table I. Clinical characteristics

\begin{tabular}{|c|c|}
\hline Variable & $\begin{array}{l}\text { Overall group } \\
\text { of patients } \\
(n=194)\end{array}$ \\
\hline Age [years] & $69.5 \pm 8.3$ \\
\hline Gender, male & $142 / 194(73.2)$ \\
\hline Hospitalization duration [days] & $7.2 \pm 3.8$ \\
\hline Body mass index $\left[\mathrm{kg} / \mathrm{m}^{2}\right]$ & $28.1 \pm 4.6$ \\
\hline $\begin{array}{l}\text { Time from the coronary artery } \\
\text { bypass grafting to bypass } \\
\text { angioplasty [years] }\end{array}$ & $12.8 \pm 5.4$ \\
\hline Obesity & $41 / 170(24.1)$ \\
\hline Smoking & $100 / 162(61.7)$ \\
\hline Anemia & $16 / 173(9.2)$ \\
\hline Hypertension & $177 / 182(97.2)$ \\
\hline Dyslipidemia & $176 / 181(97.2)$ \\
\hline Lung diseases & $16 / 177(9.0)$ \\
\hline Diabetes mellitus & $91 / 180(50.5)$ \\
\hline History of cancer & $6 / 182(3.3)$ \\
\hline $\begin{array}{l}\text { Family history of coronary arteries } \\
\text { disease }\end{array}$ & $78 / 158(49.3)$ \\
\hline Kidney failure, GFR $<60 \mathrm{ml} / \mathrm{min}$ & $44 / 173(25.4)$ \\
\hline \multicolumn{2}{|l|}{ History of: } \\
\hline $\begin{array}{l}\text { Percutaneous coronary } \\
\text { intervention }\end{array}$ & $112 / 175(64)$ \\
\hline Myocardial infarction & $144 / 179(80.4)$ \\
\hline Carotid artery atherosclerosis & $23 / 180(12.7)$ \\
\hline Lower-limb artery atherosclerosis & $39 / 180(21.7)$ \\
\hline
\end{tabular}

Data are expressed as mean $\pm S D$ or numbers (percentages). GFR glomerular filtration rate. recordings of coronary angiography were returned to the patient at discharge, which made it difficult to obtain data in the follow-up period. For this

Table II. Clinical presentation of coronary artery disease before percutaneous coronary intervention

\begin{tabular}{|c|c|}
\hline Variable & $\begin{array}{c}\text { Overall group } \\
\text { of patients } \\
(n=194)\end{array}$ \\
\end{tabular}

Clinical presentation of coronary

artery disease:

\begin{tabular}{ll}
\hline Stable angina & $66 / 186(35.5)$ \\
\hline Unstable angina & $49 / 186(26.3)$ \\
\hline $\begin{array}{l}\text { Non-ST segment elevation } \\
\text { myocardial infarction }\end{array}$ & $57 / 185(30.8)$ \\
\hline
\end{tabular}

ST-segment elevation myocardial $\quad$ 14/185 (7.6) infarction

CCS class:

\begin{tabular}{|cc|}
\hline II & $2 / 186(1.1)$ \\
\hline III & $58 / 186(31.2)$ \\
\hline Chronic heart failure: & $59 / 186(31.7)$ \\
\cline { 2 - 2 } NYHA class: & $67 / 186(36)$ \\
\cline { 2 - 2 } I & $72 / 183(39.3)$ \\
\hline II & $3 / 183(1.6)$ \\
\hline III & $48 / 183(26.2)$ \\
\hline IV & $59 / 183(32.2)$ \\
\hline
\end{tabular}

Killip class:

I 58/71 (81.7)

II 6/71 (8.4)

III $1 / 71(1.4)$

IV 6/71 (8.4)

Left ventricle ejection fraction (\%) $\quad 43.9 \pm 13.8$

\begin{tabular}{lc} 
& $45(35-55)$ \\
\hline Elevated markers of myocardial & $74 / 174(42.5)$
\end{tabular}

necrosis at admission

\begin{tabular}{|lc|}
\hline Cardiac arrest & $6 / 177(3.4)$ \\
\hline EuroSCORE II (\%) & $12.0 \pm 14.5$ \\
& $6.5(3.4-13.2)$ \\
\hline GRACE score & $124.5 \pm 31.8$ \\
& $121(105-136)$ \\
\hline Systolic blood pressure [mm Hg] & $130.6 \pm 22.8$ \\
& $130(120-140)$ \\
\hline Heart rate [beats per minute] & $71.7 \pm 13.3$ \\
& $70(60.5-80)$ \\
\hline
\end{tabular}

Data are expressed as mean $\pm S D$ and median with $I Q R$ or numbers (percentages). CCS - Canadian Cardiovascular Society, GRACE Global Registry of Acute Coronary Events, NYHA - New York Heart Association. 
reason, complete coronary artery angiography performed before $\mathrm{PCl}$ was available in 182 individuals and it revealed single-vessel disease (SVD) in $1(0.5 \%)$ patient, two-vessel disease in $14(7.7 \%)$ patients and multi-vessel disease (MVD) in 167 (91.7\%) patients. The radial access (RA) served for $\mathrm{PCl}$ in $10.8 \%$ of procedures. The target lesion treated with $\mathrm{PCl}$ was a de-novo lesion in $80.6 \%$ of patients, in-stent thrombosis in $2.1 \%$ of individuals and restenosis in $17.3 \%$ of patients. The internal mammary artery (IMA) was used as a graft in $37.1 \%$ of patients, one saphenous vein graft in $1.7 \%$, two in $49.1 \%$ of patients, three in $34.6 \%$ and four venous grafts in $14.5 \%$ of patients. The $\mathrm{PCl}$ was performed in the saphenous graft to the left anterior descending (LAD) artery in $43.9 \%$ of patients, the circumflex (CX) artery in $37.7 \%$, the right coronary artery (RCA) in $23 \%$, the left/right IMA in $4.7 \%$ and finally, the saphenous vein jump bypass graft in $4.7 \%$ of patients. Two or more bypasses were treated in $6.8 \%$ of patients while $\mathrm{PCl}$ of the second vessel (bypass or native artery) was done in $14.2 \%$ of patients. The culprit lesion was located in the proximal segment in $36.5 \%$ of cases, medial in $21.8 \%$, distal in $23.5 \%$ and unknown location in $18.2 \%$ of individuals. Unknown location meant that in the available medical records considering the description of the $\mathrm{PCl}$ procedure, there was no information regarding which graft segment was treated with angioplasty. Among the thirteen patients in the POBA/failed $\mathrm{PCl}$ group, stent crossing/deployment was not obtained in eight patients with graft stenosis, of whom there were three patients with stable angina (SA) at admission, seven with non-ST-segment elevation myocardial infarction (NSTEMI) and one with unstable angina (UA). One patient with SA developed $\mathrm{MI}$ in the follow-up period, one patient with NSTEMI died, another had MI and another cerebral stroke. The remaining 4 patients did not have MACCE. Ineffective opening of the occluded graft caused by thrombus was found in 5 patients. Two of the patients had ST-segment elevation myocardial infarction (STEMI), one of whom died during the procedure, and another one did not present MACCE during the follow-up period. Of the remaining three patients, all had NSTEMI at admission, one of them had MI in the follow-up period, and the others did not develop MACCE during the follow-up. Other procedural indices are presented in Table IV.

The overall incidence of periprocedural complications was 29 (14.9\%) out of 194 individuals. We noted 6 (3.1\%) SVG dissections, 20 (10.5\%) no-reflows, 1 (0.5\%) perforation, 3 (1.6\%) cardiac arrests, 2 (1\%) acute left ventricle failures demanding intra-aortic balloon pump, 2 (1.1\%) acute instent thromboses, 2 (1\%) bleedings requiring blood
Table III. Pharmacological therapy

\begin{tabular}{|lc|}
\hline Pharmacological therapy & $\begin{array}{c}\text { Overall group } \\
\text { of patients } \\
(n=194)\end{array}$ \\
\hline Aspirin & $185 / 188(98.4)$ \\
\hline Clopidogrel & $168 / 188(89.4)$ \\
\hline$\beta$-Blocker & $177 / 187(94.6)$ \\
\hline $\begin{array}{l}\text { Angiotensin converting enzyme } \\
\text { inhibitor }\end{array}$ & $156 / 188(83.0)$ \\
\hline Angiotensin receptor blocker & $19 / 188(10.1)$ \\
\hline Statin & $184 / 188(97.9)$ \\
\hline Nitrates & $32 / 188(17.0)$ \\
\hline $\begin{array}{l}\text { Calcium channel blockers } \\
\text { Oral anticoagulants/new oral } \\
\text { anticoagulants }\end{array}$ & $25 / 188(13.3)$ \\
\hline Prasugrel/ticagrelor & $17 / 188(9.0)$ \\
\hline $\begin{array}{l}\text { Periprocedural glycoprotein receptor } \\
\text { Ilb/llla inhibitors }\end{array}$ & $21 / 190(11.0)$ \\
\hline Data are expressed as numbers (percentages)
\end{tabular}

Data are expressed as numbers (percentages).

transfusion, 2 (1\%) respiratory insufficiencies requiring intubation and mechanical ventilation.

Long-term follow-up data were available for $156(80.4 \%)$ patients and were limited to venous grafts, also in patients treated at baseline simultaneously with $\mathrm{PCl}$ of SVG and IMA or another native artery. The mean follow-up was 964 \pm 799.1 days (ranging from 0 to 3,200 days). The study endpoints were observed in 94 (59.7\%) individuals from among all patients with completed follow-up. Among study endpoints, we noted $23(24.2 \%)$ patients with TLR, 36 (37.9\%) with TVR, 25 (26.3\%) individuals with MI, 2 (2.1\%) with CABG, 4 (4.2\%) with cerebral stroke and 29 $(30.5 \%)$ deaths. The mean time to the primary study endpoint was $669.6 \pm 598.7$ days (from 0 to 2,307 days). The mean follow-up in patients without observed study endpoints (62 individuals) was $1,326.8 \pm 859.3$ days (from 271 to 3,200 days). The Kaplan-Meier survival curve for all patients is presented in Figure 1.

The significant predictors of clinical endpoints for all variables entered, simultaneously assessed by Cox regression analysis, were in-stent thrombosis of previously implanted stent (hazard ratio (HR) $=6.97,95 \%$ confidence interval $(\mathrm{Cl}): 1.75-27.7$, $p<0.01)$, anti-embolic protection $(\mathrm{HR}=0.53$, 95\% Cl: 0.29-0.96, $p<0.05)$, direct stenting ( $\mathrm{HR}=$ $0.27,95 \% \mathrm{Cl}: 0.07-0.96, p<0.05)$, pre-dilatation $(\mathrm{HR}=0.27,95 \% \mathrm{Cl}: 0.08-0.84, p<0.05)$, no-reflow ( $H R=10.26,95 \% \mathrm{Cl}: 2.82-37.26, p<0.001)$, maximal pressure $(\mathrm{HR}=1.023,95 \% \mathrm{Cl}: 1.002-1.045$, $p<0.05)$, and number of implanted stents per patient $(\mathrm{HR}=0.36,95 \% \mathrm{Cl}: 0.15-0.83, p<0.05)$. Due 
Table IV. Procedural indices

\begin{tabular}{|c|c|}
\hline Variables & $\begin{array}{c}\text { Overall group of } \\
\text { patients } \\
(n=194)\end{array}$ \\
\hline Embolic protection devices: & $89 / 186(47.8)$ \\
\hline Filter Wire EZ (Boston Scientific, Natick, MA, USA) & $74 / 89(83.1)$ \\
\hline Proxis (St. Jude Medical, Maple Groves, MN, USA) & 9/89 (10.1) \\
\hline SpideFX (Covidien, Mansfield, MA, USA) & $4 / 89(4.5)$ \\
\hline Defender Embolic (Medtronic Inc., Minneapolis, MN, USA) & $2 / 89(2.2)$ \\
\hline Thrombus & $32 / 190(16.8)$ \\
\hline Thrombectomy & $18 / 190(9.5)$ \\
\hline \multicolumn{2}{|l|}{ Type of implanted stent: } \\
\hline Plain old balloon angioplasty/unsuccessful PCI & 21/191 (10.1) \\
\hline Drug-eluting balloon & $8 / 191(4.2)$ \\
\hline Bare-metal stent & $50 / 191(26.2)$ \\
\hline Drug-eluting stent & $111 / 191(58.1)$ \\
\hline Bioresorbable stent & $1 / 191(0.5)$ \\
\hline \multicolumn{2}{|l|}{ Number of implanted stents during single $\mathrm{PCl}$ : } \\
\hline Bare-metal stent, $n$ : & $48 / 191(25.1)$ \\
\hline 1 & $41 / 48(85.4)$ \\
\hline 2 & $6 / 48(12.5)$ \\
\hline 3 & $1 / 48(2.1)$ \\
\hline 4 & $0 / 48(0)$ \\
\hline Drug-eluting stent, $n$ & $112 / 191(58.6)$ \\
\hline 1 & $89 / 112(79.5)$ \\
\hline 2 & 20/112 (17.8) \\
\hline 3 & $0 / 112(0)$ \\
\hline 4 & $3 / 112(2.7)$ \\
\hline Bioresorbable scaffold, $n$ & $1 / 190(0.5)$ \\
\hline Mean stent diameter [mm] & $\begin{array}{l}3.4 \pm 0.6 \\
3.5(3-4)\end{array}$ \\
\hline Mean stent length [mm] & $\begin{array}{c}19.3 \pm 7.3 \\
18(15-24) \\
\end{array}$ \\
\hline Direct stenting & $53 / 186(28.5)$ \\
\hline Postdilatation & $122 / 186(65.6)$ \\
\hline Maximal pressure [atm] & $\begin{array}{c}16.3 \pm 9.6 \\
16(14-19.5) \\
\end{array}$ \\
\hline Percentage of stenosis before $\mathrm{PCl}$ & $\begin{array}{c}90.8 \pm 9.5 \\
90(90-99) \\
\end{array}$ \\
\hline Residual stenosis > 10\% after $\mathrm{PCl}$ & $14 / 188(7.4)$ \\
\hline \multicolumn{2}{|l|}{ TIMI flow grade after $\mathrm{PCl}:$} \\
\hline 0 & $6 / 189(3.2)$ \\
\hline 1 & $3 / 189(1.6)$ \\
\hline 2 & $8 / 189(4.2)$ \\
\hline 3 & $172 / 189(91)$ \\
\hline \multicolumn{2}{|l|}{ Number of stents per patient: } \\
\hline 1 & $122 / 190(64.2)$ \\
\hline 2 & $32 / 190(16.8)$ \\
\hline 3 & $4 / 190(2.1)$ \\
\hline 4 & $3 / 190(1.6)$ \\
\hline
\end{tabular}

Data are expressed as mean $\pm S D$ and median with IQR or numbers (percentages). TIMI - thrombolysis in myocardial infarction, $\mathrm{PCl}$ - percutaneous coronary intervention. 


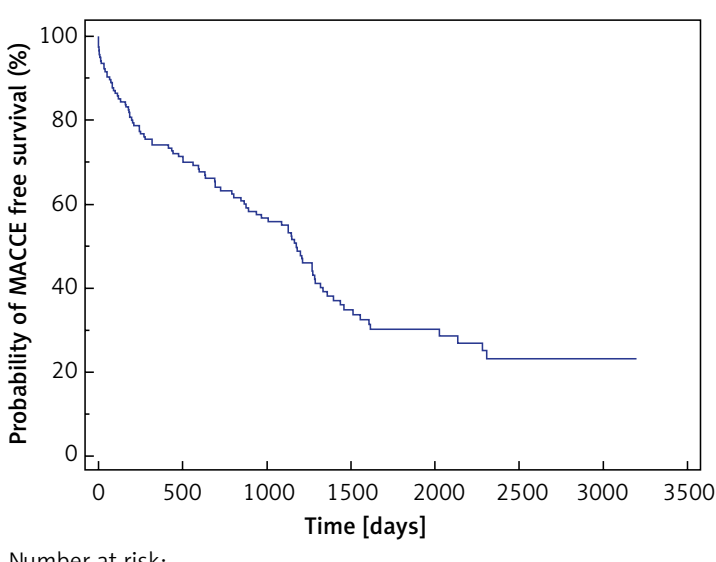

Number at risk:

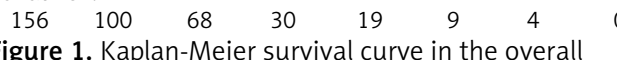
group of patients

to the fact that there are many non-significant variables that may interfere with the estimation of relevant predictors, it is difficult to interpret the results. Therefore, a model based on the retrograde correction method was constructed (where the predicate reject criterion) was the fact that its significance was above 0.10). The factors that significantly affected the incidence of endpoints were $\mathrm{PCl}$ of two or more bypasses $(\mathrm{HR}=2.89,95 \%$ $\mathrm{Cl}: 1.37-6.00, p<0.01)$, post-dilatation $(\mathrm{HR}=1.76$, $95 \% \mathrm{Cl}: 1.05-2.95, p<0.05)$ and no-reflow $(\mathrm{HR}=$ 2.16, 95\% Cl: 1.06-4.43, $p<0.05$ ) (Figure 2).

The results of the Mantel-Cox test comparing MACCE rates between particular types of $\mathrm{PCl}$ showed that $\mathrm{PCI}$ with $\mathrm{DEB}$ had significantly shorter survival times free of MACCE from $P C I$ with DES implantation $(p<0.01)$, BMS implantation $(p<$ $0.05)$ and POBA or failed PCI $(p<0.05)$ (Table V). The Breslow test (generalized Wilcoxon) results comparing MACCE rates between particular types of $\mathrm{PCl}$ revealed that $\mathrm{PCI}$ with $\mathrm{DEB}$ had significantly shorter survival times free of MACCE from patients treated with DES implantation $(p<0.05)$ and POBA or failed PCI $(p<0.05)$ (Table V). There was no significant difference in survival times free of MACCE between DES and BMS groups $(p=0.73)$ (Figure 3).

Due to the fact that MACCE occurred earlier in patients treated with $\mathrm{DEB} P \mathrm{PCI}$ when compared to non-DEB PCl, we compared the groups. In contrast to the non-DEB group, among the 8 patients included in this group, two of them presented SA at baseline, the other five UA and one patient NSTEMI. Seven patients were treated because of in-stent restenosis (87.5\%) and one patient due to in-stent thrombosis. All patients in this group were diagnosed with MACCE during the follow-up period. Although the mean time to onset of the first MACCE was insignificantly shorter in patients in the DEB group compared to the non-DEB group (633.1 \pm 602.6 days vs. $673.0 \pm 605.4$ days,

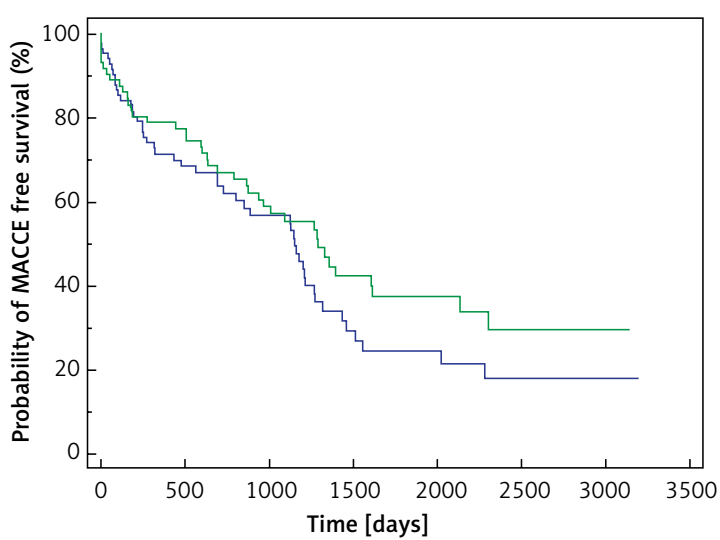

Number at risk:

\begin{tabular}{|c|c|c|c|c|c|c|c|}
\hline \multicolumn{8}{|l|}{ Group: No } \\
\hline 80 & 46 & 31 & 12 & 8 & 5 & 2 & 0 \\
\hline Group: Yes & & & & & & & \\
\hline 70 & 52 & 35 & 17 & 10 & 4 & 2 & 0 \\
\hline
\end{tabular}

Figure 2. Kaplan-Meier survival curves according to type of $\mathrm{PCl}$

$p=0.96)$, in the non-DEB group it was observed in $58.5 \%$ of patients for whom follow-up was completed compared to $100 \%$ in the DEB group. This was observed despite the fact that patients in the DEB group had lower cardiovascular risk (5.6 $\pm 2.4 \%$ vs. $13.0 \pm 15.8 \%, p=0.48)$ and statistically significantly shorter hospitalization time $(3.6 \pm 1.2$ days vs. $7.6 \pm 4.0$ days, $p<0.01$ ) when compared to the non-DEB group.

Results of the Mantel-Cox test and Breslow test comparing MACCE rates between $\mathrm{PCl}$ with and without anti-embolic protection were not significant in either estimation ( $p=0.22$ and $p=0.41$ ) (Figure 3, Table V).

\section{Discussion}

In the present study, we demonstrated that $\mathrm{PCl}$ of two or more bypasses, post-dilatation and no-reflow are negative predictors of outcomes in patients undergoing $\mathrm{PCl}$ of coronary artery bypasses. The second finding worth mentioning is that patients treated with $\mathrm{PCI}$ with DEB had worse long-term outcomes as compared to $\mathrm{PCI}$ with DES, $\mathrm{BMS}$, and even POBA and/or failed $\mathrm{PCl}$. The third is that the anti-embolic protection did not improve outcomes during follow-up.

It was reported that periprocedural necrosis during SVG $\mathrm{PCl}$ is associated with increased mortality at 1 year [10]. Also a major CK-MB release after SVG intervention is a powerful independent predictor of late mortality. Moreover, lesion length, greater angiographic degeneration of SVGs, and larger estimated plaque volume were shown to be predictors of 30-day MACE after SVG intervention [11]. We did not confirm that the extent of myocardial necrosis is related to poorer outcomes in follow-up. However, we were not able to include 
Table V. Indications and type of primary end-points according to type of $\mathrm{PCl}$ and protection status

\begin{tabular}{|c|c|c|c|c|c|c|}
\hline \multirow[t]{2}{*}{ Selected indices } & \multicolumn{6}{|c|}{ Patients with follow-up } \\
\hline & $\begin{array}{c}\text { POBA/failed } \\
\text { PCI }\end{array}$ & BMS & DES & DEB & $\begin{array}{l}\text { Protection } \\
\qquad(+)\end{array}$ & $\begin{array}{l}\text { Protection } \\
\qquad(-)\end{array}$ \\
\hline Completed follow-up & $13 / 21(61.9)$ & $39 / 50(78)$ & 95/111 (85.6) & $8 / 8(100)$ & 75/97 (77.3) & $81 / 97(83.5)$ \\
\hline $\begin{array}{l}\text { Time to primary } \\
\text { end-point [days] }\end{array}$ & $\begin{array}{c}524.7 \pm 519.7 \\
528.5 \\
(0.75-961)\end{array}$ & $\begin{array}{c}697.8 \pm 688.1 \\
503.5 \\
(108.5-1150)\end{array}$ & $\begin{array}{c}677.8 \pm 578.7 \\
569.5 \\
(128-1186.5)\end{array}$ & $\begin{array}{c}633.1 \pm 602.6 \\
425.5 \\
(86.7-1159.7)\end{array}$ & $\begin{array}{c}659.5 \pm 613.5 \\
550.5 \\
(123.7-1110.2)\end{array}$ & $\begin{array}{c}678.0 \pm 598.1 \\
519.5 \\
(112.5-1185)\end{array}$ \\
\hline \multicolumn{7}{|c|}{ Type of primary end-point: } \\
\hline All MACCE & $6 / 13(46.1)$ & 28/39 (71.8) & $52 / 95(54.4)$ & $8 / 8(100)$ & $44 / 75(58.7)$ & $50 / 81(61.7)$ \\
\hline TLR & $0 / 13(0)$ & $11 / 39(28.2)$ & $11 / 95(11.6)$ & $1 / 8(12.5)$ & $15 / 75(20)$ & $8 / 81(9.9)$ \\
\hline TVR & $0 / 13(0)$ & $14 / 39(35.9)$ & $19 / 95(20)$ & $3 / 8(37.5)$ & $20 / 75(26.7)$ & $16 / 81(19.7)$ \\
\hline $\mathrm{Ml}$ & $3 / 13(23.1)$ & 6/39 (15.4) & 13/95 (13.7) & $3 / 8(37.5)$ & $9 / 75(12)$ & $16 / 81(19.7)$ \\
\hline Cerebral stroke & $1 / 13(7.7)$ & 2/39 (5.1) & $1 / 95(1)$ & $0 / 8(0)$ & $1 / 75(1.3)$ & $3 / 81(3.7)$ \\
\hline CABG & $0 / 13(0)$ & 0/39 (0) & $2 / 95(2.1)$ & $0 / 8(0)$ & $1 / 75(1.3)$ & $1 / 81(1.2)$ \\
\hline Death & 2/13 (15.4) & 6/39 (15.4) & $6 / 95(6.3)$ & $2 / 8(25)$ & $14 / 75(18.7)$ & $15 / 81(18.5)$ \\
\hline \multicolumn{7}{|l|}{ Type of target lesion: } \\
\hline De-novo lesion & $18 / 21(85.7)$ & 47/48 (97.9) & $86 / 110(78.2)$ & $1 / 8(12.5)$ & $83 / 94(88.3)$ & $71 / 97(73.2)$ \\
\hline $\begin{array}{l}\text { In-stent } \\
\text { thrombosis }\end{array}$ & $0 / 21(0)$ & $0 / 48(0)$ & $3 / 110(2.7)$ & $1 / 8(12.5)$ & $2 / 94(2.1)$ & 2/97 (2.1) \\
\hline Restenosis & $3 / 21(14.3)$ & $1 / 48(2.1)$ & $23 / 110(20.1)$ & $6 / 8(75)$ & $8 / 94(8.5)$ & 25/97 (25.8) \\
\hline
\end{tabular}

Data are expressed as mean $\pm S D$ and median with IQR or numbers (percentages). BMS - bare-metal stent, CABG - coronary artery bypass grafting, DEB - drug-eluting balloon, DES - drug-eluting stent, MACCE - main adverse cardiac and cardiovascular event, MI - myocardial infarction, $\mathrm{PCl}$ - percutaneous coronary intervention, POBA - plain old balloon angioplasty, TLR - target lesion revascularization, TVR - target vessel revascularization.

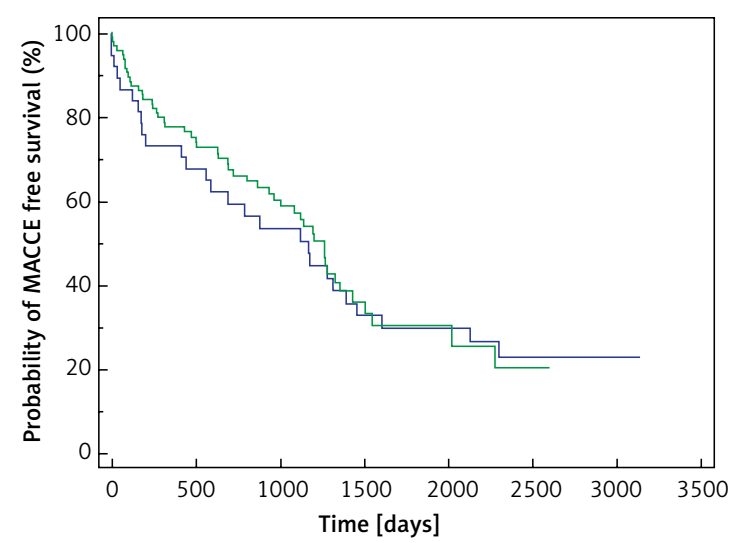

Number at risk:

\begin{tabular}{|c|c|c|c|c|c|c|c|}
\hline \multirow{4}{*}{$\begin{array}{c}\text { Group: BMS } \\
37 \\
\text { Group: DES } \\
94\end{array}$} & \multirow{2}{*}{25} & \multirow{2}{*}{18} & \multirow[b]{2}{*}{11} & \multirow[b]{2}{*}{9} & \multirow[b]{2}{*}{6} & \multirow[b]{2}{*}{2} & \multirow{3}{*}{0} \\
\hline & & & & & & & \\
\hline & & & & & & & \\
\hline & 60 & 40 & 13 & 6 & 1 & 0 & 0 \\
\hline & & type & & & $-D E$ & & \\
\hline
\end{tabular}

Figure 3. Kaplan-Meier survival curves according to the use of embolic protection devices

continuous variables of troponin level in the analysis because of the different methods of testing used over the years. The univariate analysis of the association between continuous variables of myocardial creatine kinase (CK-MB) with study endpoints revealed no significance $(p=0.17)$.
Also, dichotomous variables considering elevated markers of myocardial necrosis including troponin and CK-MB levels were not significantly associated with the study endpoints. We also did not find any relationships between gender and study endpoints in univariate analysis ( $p=0.97)$. In contrast to our study, some authors have found that female gender and renal failure are also predictors of poorer clinical outcomes after PCI of SVG [12, 13]. The univariate analysis did not confirm a significant relationship between serum creatine level ( $p=0.89)$, glomerular filtration rate assessed by the Cockcroft-Gault formula $(p=0.61)$ and dichotomous variables defining kidney failure as GFR $<60 \mathrm{ml} / \mathrm{min}(p=0.95)$. Previously reported studies revealed that poorer clinical outcomes after initial SVG intervention most frequently resulted from disease progression at untreated non-significant stenosis [14]. The results of the VELETI trial suggested that moderate stenoses should be initially treated with DES implantation [15]. In the current study, we noted TLR in 39 patients, TVR in 46 patients and re-PCl in 59 patients. Based on this, we could conclude that 20 (33.8\%) patients with TLR demanding re-PCl were not subjected to the procedure. We are not able to introduce lesions from patients demanding a CABG oper- 
ation into that comparison, but there were only two individuals in this group. Also, the 32 cases of death noted during follow-up were mostly not preceded by coronary angiography or re-PCl, and only in two cases were they followed by TVR, and in one case, TLR. Despite the use of DES, the rate of TLR remains very high and it reaches above $60 \%$ within 18 months of follow-up in the group of patients with occluded SVG [16]. Unfortunately, the addition of antithrombotic medications such as glycoprotein IIb/IIla inhibitors to filter embolic protection did not bring satisfactory results [17]. We also did not observe any effects of pre-procedural treatment with either oral coumarin derivatives or new oral anticoagulants $(p=0.91)$ and periprocedural treatment with glycoprotein $\mathrm{llb} /$ Illa inhibitors $(p=0.89)$ on study endpoints in univariate analysis. So far, the published studies have revealed significant differences in long-term outcomes between POBA and stents; however, the difference between the particular type of stents is not so clear. The SAVED trial proved the superiority of BMS implantation over POBA in terms of outcomes [18]. In our study, we revealed no statistically significant differences in clinical outcomes between PCI with DES and BMS implantation, and they were significantly better when compared to $\mathrm{PCl}$ with DEB. The results in the POBA/failed $\mathrm{PCl}$ group of patients should be treated with great caution, due to large deficiencies in the analysis and suspicion of bias in these findings. The other aspect is that in the SAVED report, the majority of SVG interventions were performed with stents. The other method of treatment is the use of covered stents. However, previously published studies did not confirm the superiority of covered stents over regular BMS implantation in SVG bypass stenoses [19]. Also, the RECOVERS trial did not confirm this relationship [20]. The use of mesh-guard stents in this group of patients is promising, as demonstrated in a recently published study [21]. The BARRICADE trial demonstrated that the TLR rate was even higher in patients treated with covered stents than those treated with BMS [22]. The superiority of DES stents over BMS was demonstrated in the RRISC trial during the 6-month follow-up and the SOS trial in 3-year follow-up [23]. However, other studies did not confirm those findings [24]. Other published meta-analyses confirmed the positive effects of DES stents on TLR, while there was no significant effect on mortality [25]. The effectiveness of $\mathrm{PCl}$ with $\mathrm{DEB}$ in patients with coronary bypasses is less investigated. Nonetheless, it was demonstrated that $\mathrm{PCI}$ with DEB brings better long-term outcomes when treating patients with BMS in-stent restenosis than DES in-stent restenosis [26]. Also, poorer outcomes were noted in patients with DEB PCl of SVG than the native arteries [26].

Despite the recommendation of international guidelines, the use of embolic protection devices is relatively rare. Previously published studies demonstrated that the use of embolic protection reached only $23 \%$ of patients undergoing $\mathrm{PCl}$ of SVG [27]. This could be explained by several disadvantages of those devices, including the need to cross the lesion before adequate protection, temporary cessation of blood flow, limiting visualization, inability to obtain full evacuation, and possible traumatic injury to the SVG during balloon occlusion [28]. Some trials did not reveal the superiority of embolic filters in comparison to the control group in terms of better clinical outcomes, and they were even associated with higher periprocedural complication rates in patients treated with filter embolic protection [29]. We also did not confirm the superiority of embolic protection filter devices used compared to the patients without protection. Additionally, similarly as in other studies, we did not find advantages of any embolic protection devices over the other ones [30].

Considering the results published so far and results of the current study, clinical outcomes in patients undergoing $\mathrm{PCl}$ of coronary artery bypasses depend on several periprocedural indices interacting with one another and leading to slow- or no-reflow. It seems that the differences between the particular stents and the use of anti-embolic protection devices are less relevant in this interaction compared to the procedure technique, which most influences the amount of debris released to the distal part of the vessel. The need for balloon post-dilatation after coronary stent deployment in native coronary arteries has been demonstrated in several studies [31], and in the case of SVG stenting, it becomes important due to the release of larger amounts of pro-embolic material, which increases the probability of slow-flow and no-reflow occurrence or strengthens it. In the present analysis, we did not find a relationship between graft age (which is indirectly associated with the amount of debris) and MACCE, as well as each of the individual components of MACCE separately. Previously published studies demonstrated that direct stenting was associated with lower periprocedural complication rates [32]. We also noted similar benefits of direct stenting in terms of longterm outcomes. However, it was only significant in the multivariate analysis model with simultaneous data assessment, and was not confirmed in a model based on the retrograde correction method. Hong et al. did not confirm a relationship between the ratio of the implanted stent diameter and the average intravascular ultrasound 
reference lumen diameter and clinical outcomes [33]. In the current study, we did not confirm a relationship between stent dimensions and clinical outcomes.

In conclusion, we demonstrated that $\mathrm{PCl}$ of two or more bypasses, post-dilatation and no-reflow are predictors of poorer clinical outcomes expressed as higher rates of TVR, TLR, MI, stroke, $C A B G$, and deaths during long-term follow-up in patients undergoing $\mathrm{PCl}$ within bypasses. Also, $\mathrm{PCl}$ with DEB was associated with poorer outcomes in patients after bypass $\mathrm{PCl}$ during follow-up compared to $\mathrm{PCl}$ with stent implantation. However, the several limitations regarding this issue should be considered, and it would be advisable to carry out studies including much larger numbers of participants with the purpose of corroborating this relationship. The use of embolic protection filters has no statistically significant effect on clinical outcomes in patients treated with $\mathrm{PCl}$ of SVG during long-term follow-up.

The most critical limitation of the current study is the relatively low percentage of completed follow-ups and the lack of clinical data in some cases (80.6\%). This was mostly caused by the participation of patients from small towns located in remote village areas or secluded areas, as well as changes in place of residence. The consequence of this may be misrepresentation of results, especially those regarding the comparison of treatment depending on the use of distal protection and the type of $\mathrm{PCl}$. In the presented analysis, the percentage of patients with implanted LIMA grafts was only $37 \%$, which is related to the period during which the material was collected (2008-2016), and in some sense includes the population of patients from the previous era. Nowadays, the proportion of patients with IMA grafts is much larger, which certainly has a significant impact on the results.

\section{Conflict of interest}

The authors declare no conflict of interest.

\section{References}

1. Fitzgibbon GM, Kafka HP, Leach AJ, Keon WJ, Hooper GD, Burton JR. Coronary bypass graft fate and patient outcome: angiographic follow-up of 5,065 grafts related to survival and reoperation in 1,388 patients during 25 years. J Am Coll Cardiol 1996; 28: 616-26.

2. Morrison DA, Sethi G, Sacks J, et al.; the VA Cooperative Study Group \#385. Percutaneous coronary intervention versus repeat bypass surgery for patients with medically refractory myocardial ischemia: AWESOME randomized trial and registry experience with post-CABG patients. J Am Coll Cardiol 2002; 40: 1951-4.

3. O'Connor GT, Malenka DJ, Quinton H, et al.; the Northern New England Cardiovascular Disease Study Group. Multivariate prediction of in-hospital mortality after percutaneous coronary interventions in 1994-1996. J Am Coll Cardiol 1999; 34: 681-91.

4. Sdringola S, Assali AR, Ghani M, et al. Risk assessment of slow or no-reflow phenomenon in aortocoronary vein graft percutaneous intervention. Catheter Cardiovasc Interv 2001; 54: 318-24.

5. Abbo KM, Dooris M, Glazier S, et al. Features and outcomes of no-reflow after percutaneous coronary intervention. Am J Cardiol 1995; 75: 778-82.

6. Barauskas M, Unikas R, Tamulenaite E, Unikaite R. The impact of clinical and angiographic factors on percutaneous coronary angioplasty outcomes in patients with acute ST-elevation myocardial infarction. Arch Med Sci Atheroscler Dis 2016; 1: e150-7.

7. Jelavic MM, Babic Z, Pintaric $H$. The importance of two metabolic syndrome diagnostic criteria and body fat distribution in predicting clinical severity and prognosis of acute myocardial infarction. Arch Med Sci 2017; 13: 795-806.

8. Burlacu A, Siriopol D, Nistor I, et al. Clinical SYNTAX Score - a good predictor for renal artery stenosis in acute myocardial infarction patients: analysis from the REN-ACS trial. Arch Med Sci 2017; 13: 837-44.

9. Januszek RA, Dziewierz A, Siudak Z, et al. Predictors of periprocedural complications in patients undergoing percutaneous coronary interventions within coronary bypass grafts. Cardiol J 2019; 26: 633-44.

10. Hong MK, Mehran R, Dangas G, et al. Creatine kinase-MB enzyme elevation following successful saphenous vein graft intervention is associated with late mortality. Circulation 1999; 100: 2400-5.

11. Giugliano GR, Kuntz RE, Popma JJ, Cutlip DE, Baim DS; Saphenous Vein Graft Angioplasty Free of Emboli Randomized (SAFER) Trial Investigators. Determinants of 30-day adverse events following saphenous vein graft intervention with and without a distal occlusion embolic protection device. Am J Cardiol 2005; 95: 173-7.

12. Ahmed JM, Dangas G, Lansky AJ, et al. Influence of gender on early and one-year clinical outcomes after saphenous vein graft stenting. Am J Cardiol 2001; 87: 401-5.

13. Lee MS, Hu PP, Aragon J, et al. Impact of chronic renal insufficiency on clinical outcomes in patients undergoing saphenous vein graft intervention with drug-eluting stents: a multicenter Southern Californian Registry. Catheter Cardiovasc Interv 2010; 76: 272-8.

14. Ellis SG, Brener SJ, DeLuca S, et al. Late myocardial ischemic events after saphenous vein graft intervention - importance of initially "nonsignificant" vein graft lesions. Am J Cardiol 1997; 79: 1460-4.

15. Rodés-Cabau J, Bertrand OF, Larose E, et al. Comparison of plaque sealing with paclitaxel-eluting stents versus medical therapy for the treatment of moderate nonsignificant saphenous vein graft lesions: the moderate vein graft lesion stenting with the Taxus stent and intravascular ultrasound (VELETI) pilot trial. Circulation 2009; 120: 1978-86.

16. Al-Lamee R, lelasi A, Latib A, et al. Clinical and angiographic outcomes after percutaneous recanalization of chronic total saphenous vein graft occlusion using modern techniques. Am J Cardiol 2010; 106: 1721-7.

17. Jonas M, Stone GW, Mehran R, et al. Platelet glycoprotein Ilb/IIla receptor inhibition as adjunctive treatment during saphenous vein graft stenting: differential effects after randomization to occlusion or filter based embolic protection. Eur Heart J 2006; 27: 920-8.

18. Savage MP, Douglas JS, Fischman DL, et al.; the Saphenous Vein De Novo Trial Investigators. Stent placement 
compared with balloon angioplasty for obstructed coronary bypass grafts. N Engl J Med 1997; 337: 740-7.

19. Turco MA, Buchbinder M, Popma JJ, et al. Pivotal, ran domized U.S. study of the Symbiot covered stent system in patients with saphenous vein graft disease: eightmonth angiographic and clinical results from the Symbiot III trial. Catheter Cardiovasc Interv 2006; 68: 379-88.

20. Stankovic G, Colombo A, Presbitero P, et al.; the RECOVERS Trial Investigators. Randomized evaluation of polytetrafluoroethylene-covered stent in saphenous vein grafts: the Randomized Evaluation of polytetrafluoroethylene COVERed stent in Saphenous vein grafts (RECOVERS) trial. Circulation 2003; 108: 37-42.

21. Vaknin-Assa H, Assali A, Lev El, et al. Long term outcomes of mguard stent deployment in saphenous vein grafts and native coronary arteries: a single center experience. Isr Med Assoc J 2017; 19: 172-6.

22. Stone GW, Goldberg S, O'Shaughnessy C, et al. Five-year follow-up of polytetrafluoroethylene-covered stents compared with bare-metal stents in aortocoronary saphenous vein graft: the randomized BARRICADE (Barrier Approach to Restenosis: Restrict Intima to Curtail Adverse Events) Trial. J Am Coll Cardiol Intv 2011; 4: 300-9.

23. Brilakis ES, Lichtenwalter C, Abdel-karim AR, et al. Continued benefit from paclitaxel-eluting compared to baremetal stent implantation in saphenous vein graft lesions during long-term follow-up of the SOS (Stenting of Saphenous Vein Grafts) trial. J Am Coll Cardiol Intv 2011; 4: 176-82.

24. Vermeersch P, Agostoni P, Verheye S, et al.; the DELAYED RRISC Investigators. Increased late mortality after sirolimus-eluting stents versus bare-metal stents in diseased saphenous vein grafts: results from the randomized DELAYED RRISC Trial. J Am Coll Cardiol 2007; 50: 261-7.

25. Hakeem A, Helmy T, Munsif S, et al. Safety and efficacy of drug eluting stents compared with bare metal stents for saphenous vein graft interventions: a comprehensive meta-analysis of randomized trials and observational studies comprising 7,994 patients. Catheter Cardiovasc Interv 2011; 77: 343-55.

26. Resch M, Ostheim P, Endemann DH, et al. Drug coated balloon is less effective for treatment of DES in-stent restenosis both in native coronary arteries and saphenous vein grafts: results from a bicenter registry. J Interv Cardiol 2016; 29: 461-8

27. Brilakis ES, Wang TY, Rao SV, et al. Frequency and predictors of drug-eluting stent use in saphenous vein bypass graft percutaneous coronary interventions: a report from the American College of Cardiology National Cardiovascular Data Cath PCI Registry. J Am Coll Cardiol Intv 2010; 3: 1068-73.

28. Lee MS, Park SJ, Kandzari DE, et al. Saphenous vein graft intervention. JACC Cardiovasc Interv 2011; 4: 831-43.

29. Carrozza JP, Mumma M, Breall JA, et al.; the PRIDE Study Investigators. Randomized evaluation of the TriActiv balloon protection flush and extraction system for the treatment of saphenous vein graft disease. J Am Coll Cardiol 2005; 46: 1677-83.

30. Mauri L, Cox D, Hermiller J, et al. The PROXIMAL trial: proximal protection during saphenous vein graft intervention using the Proxis Embolic Protection System: a randomized, prospective, multicenter clinical trial. J Am Coll Cardiol 2007; 50: 1442-9.

31. Brodie BR, Cooper C, Jones M, et al. Is adjunctive balloon postdilatation necessary after coronary stent deployment? Final results from the POSTIT trial. Catheter Cardiovasc Interv 2003; 59: 184-92.
32. Leborgne L, Cheneau E, Pichard A, et al. Effect of direct stenting on clinical outcome in patients treated with percutaneous coronary intervention on saphenous vein graft. Am Heart J 2003; 146: 501-6.

33. Hong YJ, Pichard AD, Mintz GS, et al. Outcome of undersized drug-eluting stents for percutaneous coronary intervention of saphenous vein graft lesions. Am J Cardiol 2010; 105: 179-85. 